\title{
Significance of Serum High-Density Lipoprotein Cholesterol Levels for Diagnosis of Coronary Stenosis as Determined by MDCT in Patients with Suspected Coronary Artery Disease
}

Yuhei Shiga, Shin-ichiro Miura, Ryoko Mitsutake, Akira Kawamura, Yoshinari Uehara, and Keijiro Saku

Department of Cardiology, Fukuoka University School of Medicine, Fukuoka, Japan

\begin{abstract}
Aim: Since we previously reported that lower levels of HDL-C may be most useful for predicting coronary artery disease $(\mathrm{CAD})$ as assessed by multi-detector row computed tomography (MDCT), we sought to confirm, among the levels of LDL-C, HDL-C, non-HDL-C (total cholesterol minus HDL-C) and the ratio of LDL-C to HDL-C (LDL-C/HDL-C), which is most closely related to the presence of CAD.

Methods and Results: The subjects consisted of 506 consecutive patients with suspected CAD who underwent MDCT with (+) or without (-) statin treatment. The levels of LDL-C in the statin (-) group were similar in categories I, II and III according to the Japan Atherosclerosis Society (JAS) Guidelines 2007, whereas the levels of HDL-C significantly decreased and LDL-C/HDL-C significantly increased as the category number increased. In the statin (-) group, the prevalence of CAD in categories I, II and III was 0,16 and $33 \%$, respectively ( $p=0.0018$ for trend), in patients with good control of LDL-C levels according to the Guidelines. Multivariate logistic regression analysis was performed to examine the association between the presence of CAD and 11 possible factors. Age and HDL-C in the statin (-) group, and HDL-C in the statin $(+)$ group were identified as significant independent variables that correlated with the presence of CAD. Receiver-operating characteristic curve analysis in the statin $(-)$ and statin $(+)$ groups showed a higher area under the curve for HDL-C than for LDL-C, non-HDL-C or LDL-C/HDL-C. In particular, the cut-off levels of HDL-C with the greatest sensitivity and specificity for the diagnosis of CAD in the statin $(+)$ group were 55 $\mathrm{mg} / \mathrm{dL}$ (sensitivity 0.816 , specificity 0.510 ).

Conclusions: HDL-C levels are most closely associated with the presence of CAD. In particular, we need to perform coronary CT for suspected CAD patients with lower HDL-C levels under statin treatment.
\end{abstract}

J Atheroscler Thromb, 2010; 17:870-878.

Key words; High-density lipoprotein cholesterol, Coronary artery disease, Multi-detector row computed tomography

\section{Introduction}

Many previous studies have revealed that serum levels of low- and high-density lipoprotein cholesterol (LDL-C and HDL-C, respectively) are the major pre-

Address for correspondence: Shin-ichiro Miura, Associate Professor of Medicine, Department of Cardiology, Fukuoka University School of Medicine, 7-45-1, Nanakuma, Jonan-ku,

Fukuoka, 814-0180, Japan

E-mail:miuras@cis.fukuoka-u.ac.jp

Received: September 8, 2009

Accepted for publication: January 15, 2010 dictors of atherosclerotic coronary artery disease $(\mathrm{CAD})^{1,2)}$. Multi-detector row computed tomography (MDCT) has become more widely available in many general hospitals, and enables the accurate non-invasive assessment of coronary artery stenosis ${ }^{3)}$ and calcification $^{4)}$, and plaque imaging ${ }^{5)}$ for CAD diagnosis. In addition, we previously reported that lower levels of HDL-C may be most useful for predicting CAD as assessed by MDCT, independent of metabolic factors such as adiponectin, visceral fat area or present medication ${ }^{6}$. Lower levels of HDL-C may also be an indicator of, and provide additional information regarding 
the severity of, CAD compared to other lipidemic factors $^{7)}$.

The level of LDL-C or HDL-C is an independent risk factor for CAD. Although lower values for the ratio of LDL-C to HDL-C (LDL-C/HDL-C) in addition to a greater percentage increase in HDL-C and lower levels of LDL-C in patients during treatment with statins have been associated with the regression of atheroma ${ }^{8)}$, few reports have discussed whether LDL-C/HDL-C or non-HDL-C (total cholesterol minus HDL-C) is a risk factor ${ }^{9,10)}$; therefore, we determined, among the levels of LDL-C, HDL-C, nonHDL-C and LDL-C/HDL-C, which is most closely related to the presence of CAD.

\section{Methods}

\section{Study Subjects}

Five hundred six consecutive subjects who were clinically suspected of having CAD or who had at least one cardiac risk factor were enrolled in this study. All subjects underwent MDCT coronary angiography between July 2006 and August 2008. We excluded patients with anti-lipidemic therapy, except for statins, from the present study. Patients with $\mathrm{Cr}>2.0 \mathrm{mg} / \mathrm{dL}$ and contrast-induced allergy did not undergo MDCT. The protocol in this study was approved by the ethics committee of Fukuoka University Hospital, and all subjects gave their informed consent to participate.

\section{Evaluation of Coronary Stenosis Using MDCT}

We evaluated coronary stenosis using MDCT as previously described ${ }^{11)}$. Briefly, all patients were scanned by 64-MDCT on an Aquilion 64 (TOSHIBA, Tokyo, Japan). The use of beta-blockers and nitroglycerin before scanning was left to the physician's discretion. A 70-mL bolus of contrast media (Omnipaque, $350 \mathrm{mg}$ iodine/mL; Daiichi Sankyo Co., Ltd., Tokyo, Japan) was injected at a flow rate of $3.6 \mathrm{~mL} / \mathrm{sec}$, followed by $35 \mathrm{~mL}$ contrast agent and $30 \mathrm{~mL}$ saline solution, each at a flow rate of $1.8 \mathrm{~mL} / \mathrm{sec}$, with a dual injector. The region of interest was placed within the ascending aorta, and the scan was started when the CT density reached 100 Hounsfield Units higher than the baseline CT density. The scan was performed between the tracheal bifurcation and diaphragm with the following parameters: collimation width $0.5 \mathrm{~mm}$, rotation speed $0.4 \mathrm{sec} /$ rotation, tube voltage $135 \mathrm{kV}$, and effective tube current $360 \mathrm{~mA}$.

All segments were assessed according to the 15-segment American Heart Association (AHA) coronary artery model ${ }^{12)}$. Since $85(16.8 \%)$ patients had at least one unevaluable segment on MDCT because of severe calcification and motion artifacts, they could not be evaluated by MDCT. Overall, 15 coronary artery segments of 506 patients (total 7,590) were assessed. Of these 7,590 segments, 109 (1.4\%) and $232(3.1 \%)$ segments could not be evaluated by MDCT because of severe calcification and motion artifacts, respectively; thus, we used 7,249 segments $(95.5 \%)$ for analysis. Any narrowing of the normal contrast-enhanced lumen to $<50 \%$ that could be identified in multiplanar reconstructions or cross-sectional images was defined as significant stenosis in CAD.

\section{Evaluation of CAD Risk Factors}

Body mass index (BMI), systolic blood pressure (SBP), diastolic blood pressure (DBP), serum levels of total cholesterol (TC) triglycerides (TG), HDL-C, LDL-C, LDL-C/HDL-C, non HDL-C (TC minus HDL-C), uric acid (UA), fasting glucose, hemoglobin A1c (HbA1c), smoking status (current versus nonsmokers), family history [myocardial infarction (MI), angina pectoris or sudden death], and medication use were collected as CAD factors in all patients.

BMI was calculated as weight $(\mathrm{kg}) /$ height $(\mathrm{m})^{2}$. $\mathrm{BP}$ was determined as the mean of two measurements obtained in an office setting by the conventional cuff method using a mercury sphygmomanometer after at least 5 minutes of rest. All blood samples were drawn in the morning after the patients had fasted overnight. The characteristics of patients were obtained from medical records with regard to the history of hypertension (HT), dyslipidemia (DL), diabetes mellitus (DM), and history of smoking. Patients who had a current SBP/DBP $\geq 140 / 90 \mathrm{mmHg}$ or who were receiving antihypertensive therapy were considered to have HT. Patients with LDL-C $\geq 140 \mathrm{mg} / \mathrm{dL}$, TG $\geq 150 \mathrm{mg} / \mathrm{dL}$, and/or HDL-C $<40 \mathrm{mg} / \mathrm{dL}$ or who were receiving lipid-lowering therapy, were considered to have $\mathrm{DL}^{13)}$. DM was defined using the American Diabetes Association criteria ${ }^{14)}$ or by the administration of a glucose-lowering drug. Hyperuricemia (HU) was defined as a serum uric acid level of $\geq 7.0 \mathrm{mg} / \mathrm{dL}$ or the administration of uric acid-lowering drugs.

\section{Diagnostic Criteria for Metabolic Syndrome (MetS)}

MetS was diagnosed by the modified guidelines ${ }^{15)}$ : visceral fat area (VFA) $\geq 100 \mathrm{~cm}^{2}$ and the presence of two or more of the following: high $\mathrm{BP}$ (SBP $\geq 130 \mathrm{mmHg}$ or DBP $\geq 85 \mathrm{mmHg}$ or taking an anti-hypertensive drug), DL (TG $\geq 150 \mathrm{mg} / \mathrm{dL}$ or 40 $\mathrm{mg} / \mathrm{dL}>\mathrm{HDL}-\mathrm{C}$ ) or high fasting glucose (fasting glucose $\geq 110 \mathrm{mg} / \mathrm{dL}$ or taking a glucose-lowering drug). Subjects were classified according to the number of these components of MetS. For the measure- 
Table 1. Patient Characteristics

\begin{tabular}{lccc}
\hline Age, yrs & $64 \pm 11$ & DM, \% & 43 \\
Sex (male), \% & 54 & HbAlc, \% & $6.7 \pm 2.0$ \\
Family history, \% & 15 & Fasting glucose, mg/dL & $125 \pm 52$ \\
Smoking, \% & 32 & HU, \% & 14 \\
BMI, kg/m² & $24 \pm 4$ & Uric acid, mg/dL & $5.3 \pm 1.5$ \\
HT, \% & 69 & Medication use, \% & \\
$\quad$ SBP, mmHg & $136 \pm 20$ & ARB/ACEI & 39 \\
DBP, mmHg & $79 \pm 11$ & CCB & 40 \\
DL, \% & 60 & Statin & 30 \\
TG, mg/dL & $130 \pm 73$ & SFA, cm ${ }^{2}$ & $156 \pm 77$ \\
HDL-C, mg/dL & $55 \pm 17$ & VFA, cm ${ }^{2}$ & $122 \pm 63$ \\
LDL-C, mg/dL & $119 \pm 33$ & WC, cm & $91 \pm 11$ \\
LDL-C/HDL-C & $2.4 \pm 1.0$ & CAD, $\%$ & 28 \\
Non HDL-C & $146 \pm 37$ & MetS, \% & 35 \\
\hline
\end{tabular}

Continuous variables are expressed as the mean \pm SD. BMI, body mass index; HT, hypertension; SBP, systolic blood pressure; DBP, diastolic blood pressure; DL, dyslipidemia; TG, triglyceride; HDL-C, high density lipoprotein cholesterol; LDL-C, low density lipoprotein cholesterol; LDL-C/ HDL-C, a ratio of LDL-C to HDL-C; Non HDL-C, total cholesterol minus HDL-C; DM, diabetes mellitus; HU, hyperuricemia; ARB, angiotensin II receptor blocker; ACEI, angiotensin-converting enzyme inhibitor; CCB, calcium channel blocker; SFA; subcutaneous fat area; VFA, visceral fat area; WC, waist circumference; CAD, coronary artery disease; MetS, metabolic syndrome.

ment of the visceral fat area (VFA), subcutaneous fat area (SFA), and waist circumference, CT scan was performed. These values were measured from CT crosssectional scans at the level of the umbilicus using software (Fat Scan; N2 System, Hyogo, Japan).

\section{Statistical Analysis}

Statistical analysis was performed using Excel 2003 (SSRI, Tokyo, Japan) and Stat View statistical software package (Stat View 5; SAS Institute Inc., Cary, NC, USA) at Fukuoka University (Fukuoka, Japan). Data are shown as the mean \pm standard deviation (SD). Categorical and continuous variables were compared between groups by chi-square analysis and analysis of variance followed by Fisher's PLSD, respectively. Receiver-operating characteristic (ROC) curve analysis was used to determine the cut-off of HDL-C, LDL-C, LDL-C/HDL-C, and non-HDL-C to distinguish between the presence and absence of CAD at the highest possible sensitivity and specificity levels. Multivariate analysis was performed by logistic regression analysis for independent variables that were related to the presence or absence of CAD. A value of $p<0.05$ was considered significant.

\section{Results}

\section{Patient Characteristics}

Table 1 shows the clinical characteristics of the
506 patients, who consisted of $273(54 \%)$ men and $233(46 \%)$ women. The prevalence of HT, DL and DM was $69 \%, 60 \%$ and $43 \%$, respectively. The mean age was $64 \pm 11$ years, BMI was $24 \pm 4 \mathrm{~kg} / \mathrm{m}^{2}$, and VFA was $122 \pm 63 \mathrm{~cm}^{2}$. In addition, the percentage use of angiotensin II receptor blocker (ARB)/angiotensin-converting enzyme inhibitor (ACEI), calcium channel blocker (CCB), and statin was 39\%, 40\% and $30 \%$, respectively.

\section{Lipid Profile and Prevalence of CAD with or without Statin Treatment in Each Category}

As shown in Table 2, we analyzed lipidemic parameters and the prevalence of the presence of CAD with or without statin treatment [statin $(+)$ group or statin (-) group] in categories I (low-risk group), II (intermediate-risk group) and III (high-risk group) according to the Japan Atherosclerosis Society (JAS) Guidelines $2007^{10)}$. The levels of LDL-C and nonHDL-C in the statin (-) group were similar in categories I, II and III, whereas the levels of HDL-C significantly decreased ( $p<0.0001$ for trend) and LDL-C/ HDL-C and TG significantly increased as the category number increased $(p=0.0003$ and $p=0.0007$ for trend, respectively). In addition, the prevalence of CAD in categories I, II and III was 0, 16 and 33\%, respectively ( $p=0.002$ for trend) in patients with good control of LDL-C levels according to the JAS Guidelines 2007. In the statin (+) group, none of the 
Table 2. Lipid profile and prevalence of CAD with $(+)$ or without $(-)$ statin treatment in each category

\begin{tabular}{|c|c|c|c|c|c|c|}
\hline \multirow[b]{2}{*}{ Category } & \multicolumn{4}{|c|}{ Statin $(-)$ group } & \multicolumn{2}{|c|}{ Statin $(+)$ group } \\
\hline & $\begin{array}{c}\mathrm{I} \\
(n=8)\end{array}$ & $\begin{array}{c}\text { II } \\
(n=160)\end{array}$ & $\begin{array}{c}\text { III } \\
(n=186)\end{array}$ & $\begin{array}{l}p \text { value } \\
\text { for trend }\end{array}$ & $\begin{array}{c}\text { II } \\
(n=51)\end{array}$ & $\begin{array}{c}\text { III } \\
(n=101)\end{array}$ \\
\hline LDL-C, mg/dL & $115 \pm 38$ & $122 \pm 34$ & $115 \pm 31$ & 0.202 & $119 \pm 45$ & $147 \pm 31^{*}$ \\
\hline HDL-C, mg/dL & $74 \pm 30$ & $61 \pm 17$ & $50 \pm 15^{*}$ & $<0.0001$ & $58 \pm 12$ & $52 \pm 16^{*}$ \\
\hline $\mathrm{TG}, \mathrm{mg} / \mathrm{dL}$ & $82 \pm 46$ & $112 \pm 68$ & $140 \pm 82^{*}$ & 0.0007 & $119 \pm 45$ & $147 \pm 67^{*}$ \\
\hline LDL-C/HDL-C & $1.6 \pm 0.5$ & $2.0 \pm 0.8$ & $2.3 \pm 1.0 *$ & 0.0003 & $2.1 \pm 1.0$ & $2.8 \pm 1.1^{*}$ \\
\hline Non HDL-C & $137 \pm 49$ & $147 \pm 37$ & $144 \pm 36$ & 0.622 & $143 \pm 34$ & $152 \pm 38$ \\
\hline VFA, & $73 \pm 62$ & $101 \pm 60$ & $133 \pm 63^{*}$ & $<0.0001$ & $112 \pm 39$ & $139 \pm 66^{*}$ \\
\hline MetS, \% & 0 & 8 & $54^{*}$ & $<0.0001$ & 18 & $54^{*}$ \\
\hline \multicolumn{7}{|l|}{$\mathrm{CAD}, \%$} \\
\hline All & 0 & 17 & 35 & 0.0002 & 25 & 36 \\
\hline Good & 0 & 16 & 33 & 0.002 & 25 & 34 \\
\hline Poor & 0 & 22 & 60 & 0.009 & 29 & 43 \\
\hline
\end{tabular}

LDL-C, low density lipoprotein cholesterol; HDL-C, high density lipoprotein cholesterol; TG, triglyceride; LDL-C/HDL-C, a ratio of LDL-C to HDL-C; Non HDL-C, total cholesterol minus HDL-C; CAD, coronary artery disease. \% CAD in all patients (All), patients with good control (Good) and poor control (Poor) in LDL-C levels according to the JAS Guidelines $2007 .{ }^{*} p<0.05$ vs. group I and/or II.

patients were in category I. Patients in category III showed significantly higher levels of LDL-C, TG and LDL-C/HDL-C and lower levels of HDL-C than those in category II, and $36 \%$ of the patients in category III had CAD, whereas there was no difference in the levels of non-HDL-C between category II and III.

\section{Lipid Profile with or without Statin Treatment in the Presence or Absence of CAD}

Fig. 1 shows lipid profiles in the presence or absence of CAD in statin (-) and statin (+) groups. There were no differences in the levels of LDL-C between the presence and absence of CAD in statin (-) and $(+)$ groups. Patients with CAD in statin $(-)$ and $(+)$ groups had significantly lower levels of HDL-C and higher levels of LDL-C/HDL-C, while there were no differences in the levels of non-HDL-C between the presence and absence of CAD in statin $(-)$ and statin (+) groups (data not shown).

\section{LDL-C Levels and the Prevalence of CAD According to HDL-C Levels}

As shown in Fig. 2, we divided the patients in statin $(-)$ and $(+)$ groups into four groups according to HDL-C levels $(<40 \mathrm{mg} / \mathrm{dL}, 40-49,50-59, \geq 60)$ because Mabuchi et al. reported that each $10 \mathrm{mg} / \mathrm{dL}$ increase in HDL-C concentration reduced the risk of CAD by $28.3 \%{ }^{16)}$. There were no differences in LDL-C levels among the 4 categories in statin $(-)$ and $(+)$ groups. The presence of CAD significantly increased as HDL-C levels decreased in statin $(-)$ and
(+) groups. The prevalence of CAD among the 4 categories in the statin $(-)$ group was $38,29,25$ and $18 \%$, respectively $(p=0.0002$ for trend). The statin $(+)$ group also showed a significant trend $(p=0.002)$.

\section{Comparison of Parameters with Regard to the Presence of CAD}

Since LDL-C/HDL-C levels were significantly associated with both HDL-C [statin $(-)$ group, $r=$ $-0.675, p<0.0001$; statin (+) group, $r=-0.679$, $p<$ $0.0001)$ ] and LDL-C levels [statin (-) group, $r=$ $0.694, p<0.0001$; statin (+) group, $r=0.693$, $p<$ $0.0001]$, and since non-HDL-C levels were significantly associated with LDL-C [statin (-) group, $r=$ $0.896, p<0.0001$; statin (+) group, $r=0.913, p<$ $0.0001)]$, we excluded LDL-C/HDL-C and nonHDL-C from multivariate logistic regression analysis. Analysis was performed to examine the association between the presence of $\mathrm{CAD}$ and 11 possible factors, as determined in Table 3. Age $(p=0.0003)$ and HDL-C $(p=0.039)$ in the statin $(-)$ group and HDL-C $(p=0.0007)$ in the statin $(+)$ group were identified as significant independent variables that correlated with the presence of CAD. The presence of CAD was not associated with LDL-C in statin (-) $(p=0.203)$ and statin $(+)(p=0.757)$ groups.

\section{Cut-Off Value of HDL-C for Diagnosis of CAD}

ROC curve analysis in statin (-) and statin (+) groups showed a higher area under the curve for HDL-C (0.598 and 0.671, respectively) than for 
a. LDL-C

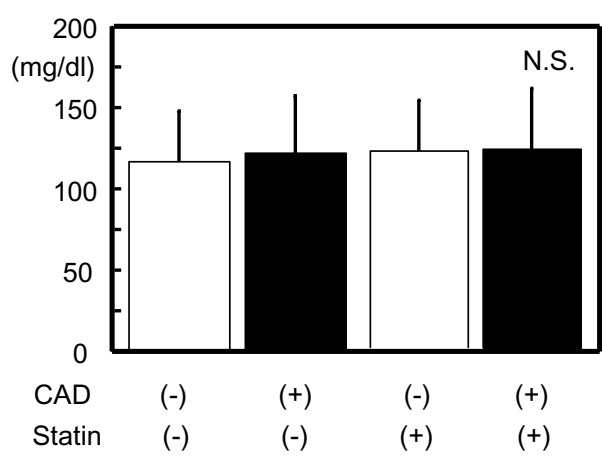

c. TG



b. HDL-C

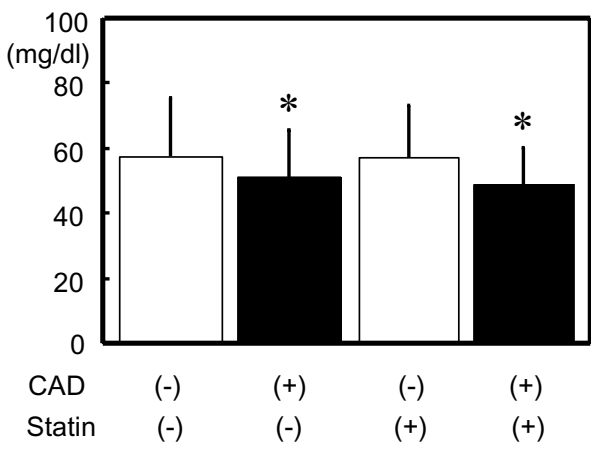

d. LDL-C/HDL-C

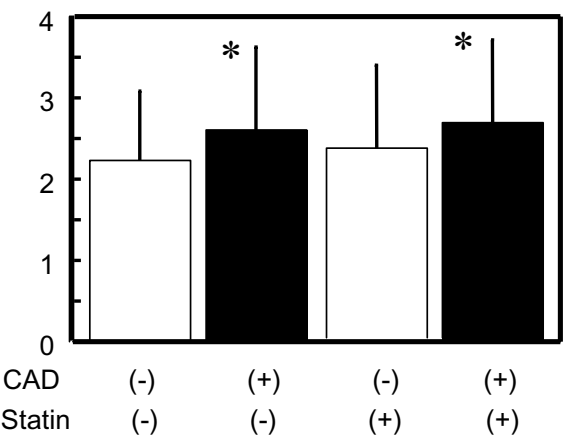

Fig. 1. Serum levels of LDL-C (a), HDL-C (b), TG (c) and LDL/HDL (d) in statin (-) and statin $(+)$ groups. Open and closed bars indicate CAD (-) and CAD (+). N.S., not significant. ${ }^{*} p<0.05$ vs. CAD (-).

LDL-C (0.453 and 0.514, respectively), LDL-C/ HDL-C (0.388 and 0.398 , respectively) or nonHDL-C (0.439 and 0.483, respectively) (Fig. 3), indicating that HDL-C levels may be a more useful lipidemic marker than LDL-C, LDL-C/HDL-C or nonHDL-C levels. The cut-off levels of HDL-C with the greatest sensitivity and specificity for the diagnosis of CAD in the statin $(-)$ and statin $(+)$ groups were 43 $\mathrm{mg} / \mathrm{dL}$ (sensitivity 0.391 , specificity 0.785 ) and 55 $\mathrm{mg} / \mathrm{dL}$ (sensitivity 0.816 , specificity 0.510 ), respectively.

\section{Discussion}

In the present study, the presence of CAD significantly increased as HDL-C levels decreased in statin $(-)$ and $(+)$ groups. In addition, age and HDL-C in the statin (-) group and HDL-C in the statin (+) group were identified as significant independent factors that correlated with the presence of CAD. Finally, ROC analysis indicated that HDL-C levels may be a more useful lipidemic marker than LDL-C, LDL-C/ $\mathrm{HDL}-\mathrm{C}$ or non-HDL-C levels for predicting CAD in statin (-) and (+) groups.

The 11 factors in Table 3, except for TG, are independent risk factors for $\mathrm{CAD}^{11,17)}$. Although there is reportedly an association between the TG level and morbidity of $\mathrm{CAD}^{18,19)}$, this issue remains controversial. In this study, age and HDL-C in the statin (-) group, and HDL-C in the statin (+) group were identified as independent risk factors for CAD. Age is a risk factor for the progression of atherosclerosis ${ }^{20)}$ and was an independent risk factor in the statin (-) group. The mortality and morbidity rates of CAD increased after age 45 years in males and 55 years in females ${ }^{21}$. Although the average age in this study (64 \pm 11 years) was higher than these ages, age was not an independent risk factor in the statin (+) group. Statin treatment contributes to enhanced endothelial nitric oxide synthase (eNOS) expression and $\mathrm{NO}$ release ${ }^{22)}$, and has anti-proliferation and anti-inflammatory activity through the downregulation of adhesion molecules and chemokines $\left.{ }^{23}, 24\right)$. Since these effects may induce an anti-aging effect on the vasculature, statin treatment may inhibit the adverse effect of aging-induced $\mathrm{CAD}$, and lower levels of HDL-C may become the 
a. Statin (-) group


HDL-C $(\mathrm{mg} / \mathrm{dl})$

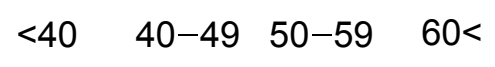

b. Statin $(+)$ group
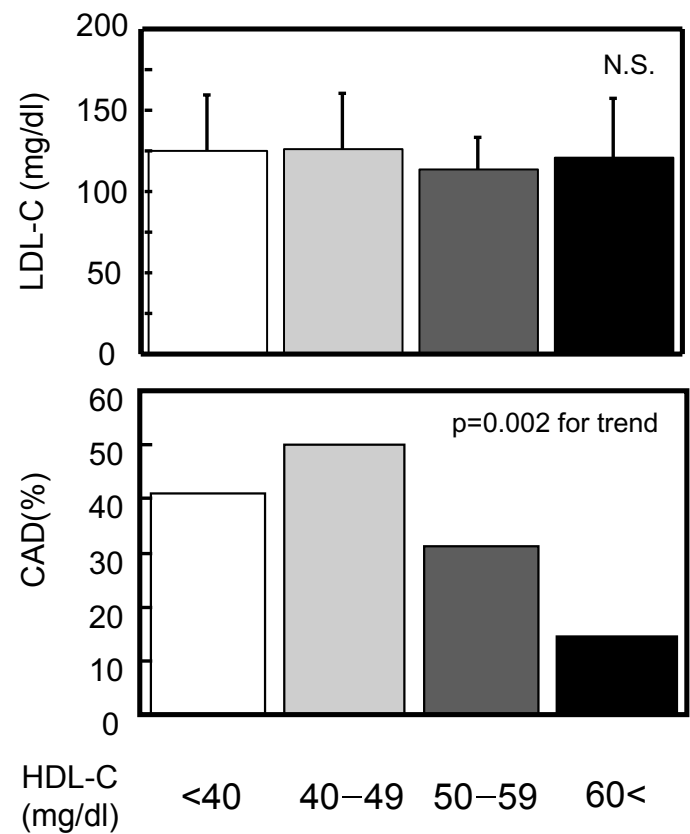

Fig. 2. LDL-C levels and the prevalence of CAD according to HDL-C levels. Patients in the a) statin (-) and b) statin $(+)$ groups were divided into 4 groups according to HDL-C levels $(<40 \mathrm{mg} / \mathrm{dL}$, $40-49 \mathrm{mg} / \mathrm{dL}, 50-59 \mathrm{mg} / \mathrm{dL}, \geq 60 \mathrm{mg} / \mathrm{dL}$ ). N.S., not significant.

Table 3. Comparison of parameters with regard to the presence of CAD

\begin{tabular}{|c|c|c|c|c|}
\hline & \multicolumn{2}{|c|}{ Statin $(-)$ group } & \multicolumn{2}{|c|}{ Statin $(+)$ group } \\
\hline & OR $(95 \% \mathrm{CI})$ & $p$ value & OR $(95 \% \mathrm{CI})$ & $p$ value \\
\hline Age & $1.05(1.02-1.09)$ & 0.0003 & $1.00(0.96-1.05)$ & 0.894 \\
\hline Smoking & $1.63(0.92-2.90)$ & 0.095 & $0.50(0.20-1.23)$ & 0.132 \\
\hline Family & $1.07(0.50-2.30)$ & 0.859 & $1.16(0.42-3.19)$ & 0.780 \\
\hline SBP & $1.02(0.99-1.04)$ & 0.057 & $1.02(0.99-1.05)$ & 0.232 \\
\hline DBP & $1.00(0.97-1.04)$ & 0.897 & $0.99(0.94-1.05)$ & 0.798 \\
\hline HbAlc & $1.09(0.87-1.36)$ & 0.445 & $1.04(0.83-1.31)$ & 0.713 \\
\hline Fasting blood glucose & $1.00(0.99-1.01)$ & 0.557 & $1.00(0.99-1.01)$ & 0.724 \\
\hline Visceral fat area & $1.00(1.00-1.00)$ & 0.824 & $1.00(0.99-1.01)$ & 0.635 \\
\hline LDL-C & $1.01(1.00-1.01)$ & 0.203 & $1.00(0.99-1.01)$ & 0.757 \\
\hline HDL-C & $0.98(0.960-0.999)$ & 0.039 & $0.94(0.91-0.98)$ & 0.0007 \\
\hline TG & $1.00(1.00-1.01)$ & 0.356 & $1.00(0.99-1.01)$ & 0.988 \\
\hline
\end{tabular}

$\mathrm{CAD}$, coronary artery disease; SBP, systolic blood pressure; DBP, diastolic BP; HbA1c, hemoglobin A1c; LDL-C, low density lipoprotein cholesterol; HDL-C, high density lipoprotein cholesterol; TG, triglyceride. OR, odds ratio; CI, confidence interval.

strongest risk factor in the statin (+) group.

The level of LDL-C was not a main risk factor for CAD in either the statin (-) or statin (+) group in this study. Statin treatment reduces the level of LDL-C by about $30 \%$ from the baseline ${ }^{25,26)}$. As shown in Fig. 1, there were no differences in the level of LDL-C between the presence and absence of CAD in statin (-) and statin (+) groups. When the level of LDL-C is reduced to around $120 \mathrm{mg} / \mathrm{dL}$ by statins, HDL-C may appear to become a stronger risk factor for $\mathrm{CAD}$ than LDL-C because the HDL-C level in CAD (+) is significantly lower than in CAD (-) (Fig. 1). Since the $\mathrm{LDL} / \mathrm{HDL}$ ratio in the CAD (-) group was 2.1, aggressive statin treatment is needed to reach this ratio. 
a. Statin (-) group

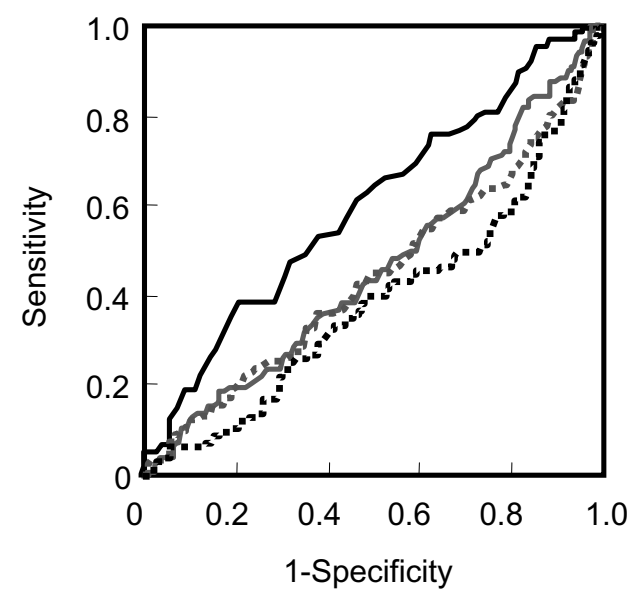

b. Statin (+) group

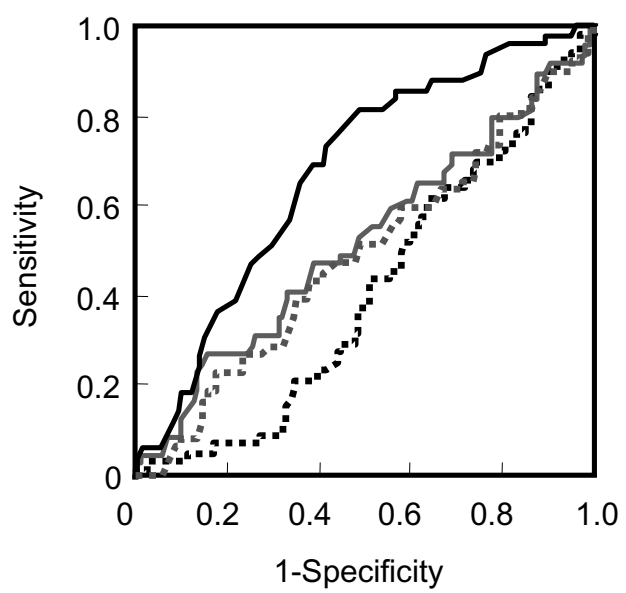

Fig. 3. Receiver-operating characteristic (ROC) curve for HDL-C (black lines), LDL-C (gray lines), non-HDL-C (gray dotted lines), and LDL-C/HDL-C (black dotted lines) levels forthe diagnosis of CAD in a) statin (-) and b) statin (+) groups.

When the LDL/HDL ratio was $>2.0$ during statin treatment, the atheroma volume increased $(+1.2 \%)$, and LDL/HDL $<1.5$ showed the regression of atheroma $(-0.3 \%)^{8)}$. Even if a patient reaches an LDL/ HDL ratio of 2.1, such a patient may develop CAD in the near future.

In the statin (-) group, the LDL-C level was about $120 \mathrm{mg} / \mathrm{dL}$ in categories I, II and III. Nonetheless, $16 \%$ and $33 \%$ of patients with good control of LDL-C levels according to the JAS Guidelines 2007 in categories II and III in the statin (-) group had CAD, respectively. In primary prevention, although patients in categories II and III without statins need to have improved HDL function, there are currently only a few therapeutic strategies for improving this function, such as the use of statins and cholesterol ester transfer protein inhibitor. The increases in HDL-C levels in REVERSAL ${ }^{27)}$, CAMELOT ${ }^{28)}$ and ACTIVATE $^{29)}$ were $1.9,1.7$ and $1.2 \mathrm{mg} / \mathrm{dL}$, respectively, and these increments may not be enough to prevent CAD. Only rosuvastatin increased the HDL-C level by $5.7 \mathrm{mg} / \mathrm{dL}$ in ASTEROID ${ }^{30)}$. Significant increases in HDL-C may regress atherosclerosis. Alternatively, a further reduction of LDL-C levels may be needed.

There are several limitations of this study. First, although the subjects in this study were clinically suspected of having CAD, over half of the subjects were considered to not have CAD by MDCT. Second, although coronary stenosis with severe coronary calcification was not evaluated using MDCT, recent studies have shown that both the sensitivity and specificity of MDCT for the identification of significant coronary stenosis were approximately $95 \%$, compared with invasive coronary angiography ${ }^{31)}$. In this study, we could evaluate $95.5 \%$ of all segments. Third, this study was cross-sectional. Although it takes a long time for coronary atherosclerosis to progress, we only analyzed the prevalence, the control situation, and the medications presently used to treat HT, DM and DL, and we did not have data on the duration of these diseases and medications.

In conclusion, age and HDL-C in the statin (-) group and HDL-C in the statin (+) group were identified as significant independent factors that correlated with the presence of CAD. In particular, we need to perform coronary CT for suspected CAD patients with lower levels of serum HDL-C under statin treatment.

\section{Conflict of Interest}

The authors declare no conflict of interest.

\section{References}

1) Gordon T, Castelli WP, Hjortland MC, Kannel WB, Dawber TR: High density lipoprotein as a protective factor against coronary heart disease. The Framingham Study. Am J Med, 1977; 62: 707-714

2) Assmann G, Cullen P, Kannenberg F, Schulte H: Relationship between phytosterol levels and components of the metabolic syndrome in the PROCAM study. Eur J Cardiovasc Prev Rehabil, 2007; 14: 208-212

3) Rumberger JA, Sheedy PF 3rd, Breen JF, Schwartz RS: 
Coronary calcium, as determined by electron beam computed tomography, and coronary disease on arteriogram. Effect of patient's sex on diagnosis. Circulation, 1995; 91: 1363-1367

4) Nitta K, Akiba T, Suzuki K, Uchida K, Ogawa T, Majima K, Watanabe R, Aoki T, Nihei H: Assessment of coronary artery calcification in hemodialysis patients using multidetector spiral CT scan. Hypertens Res, 2004; 27: $527-$ 533

5) Achenbach S, Ropers D, Hoffmann U, MacNeill B, Baum U, Pohle K, Brady TJ, Pomerantsev E, Ludwig J, Flachskampf FA, Wicky S, Jang IK, Daniel WG: Assessment of coronary remodeling in stenotic and nonstenotic coronary atherosclerotic lesions by multidetector spiral computed tomography. J Am Coll Cardiol, 2004; 43: $842-847$

6) Mitsutake R, Miura S, Kawamura A, Saku K: Are metabolic factors associated with coronary artery stenosis on MDCT? Circ J, 2009; 73: 132-138

7) Mitsutake R, Miura S, Zhang B, Saku K: HDL-associated factors provide additional prognostic information for coronary artery disease as determined by multi-detector row computed tomography. Int J Cardiol, 2009. in press

8) Nicholls SJ, Tuzcu EM, Sipahi I, Grasso AW, Schoenhagen $\mathrm{P}, \mathrm{Hu}$ T, Wolski K, Crowe T, Desai MY, Hazen SL, Kapadia SR, Nissen SE: Statins, high-density lipoprotein cholesterol, and regression of coronary atherosclerosis. JAMA, 2007; 297: 499-508

9) Sugimoto K, Isobe K, Kawakami Y, Yamada N: The relationship between non-HDL cholesterol and other lipid parameters in Japanese subjects. J Atheroscler Thromb, 2005; 12: 107-110

10) Shimano H, Arai $H$, Harada-Shiba M, Ueshima $H$, Ohta T, Yamashita S, Gotoda T, Kiyohara Y, Hayashi T, Kobayashi J, Shimamoto K, Bujo H, Ishibashi S, Shirai K, Oikawa S, Saito Y, Yamada N: Proposed guidelines for hypertriglyceridemia in Japan with non-HDL cholesterol as the second target. J Atheroscler Thromb, 2008; 15: $116-121$

11) Mitsutake R, Niimura $H$, Miura $S$, Zhang B, Iwata $A$, Nishikawa H, Kawamura A, Kumagai K, Shirai K, Matsunaga A, Saku K: Clinical significance of the coronary calcification score by multidetector row computed tomography for the evaluation of coronary stenosis in Japanese patients. Circ J, 2006; 70: 1122-1127

12) Dodge JT Jr, Brown BG, Bolson EL, Dodge HT: Intrathoracic spatial location of coronary segments on the normal human heart. Circulation, 1988; 78: 1167-1180

13) The Japan Atherosclerosis Society: Chapter 3. Goals of Dislipidemia Management. J Atheroscler Thromb, 2009; 16 Sup: $15-25$

14) American Diabetes Association: Screening for type 2 diabetes. Diabetes Care, 2004; 27 Sup 1: S11-14

15) Examination committee of criteria for diagnosis of metabolic syndrome in Japan. Definition and criteria for diagnosis of metabolic syndrome. J Jpn Soc Int Med, 2005; 94: 794-809. in Japanese

16) Mabuchi H, Kita T, Matsuzaki M, Matsuzawa $Y$, Nakaya N, Oikawa S, Saito Y, Sasaki J, Shimamoto K, Itakura H; J-LIT Study Group: Japan Lipid Intervention Trial. Large scale cohort study of the relationship between serum cholesterol concentration and coronary events with low-dose simvastatin therapy in Japanese patients with hypercholesterolemia and coronary heart disease: secondary prevention cohort study of the Japan Lipid Intervention Trial (J-LIT). Circ J, 2002; 66: 1096-1100

17) The Japanese Society of Hypertension Committee for Guidelines for the Management of Hypertension. Chapter 2. Measurement and clinical evaluation of blood pressure. Hypertens Res, 2009; 32: 11-23

18) Satoh H, Nishino T, Tomita K, Tsutsui H: Fasting triglyceride is a significant risk factor for coronary artery disease in middle-aged Japanese men. Circ J, 2006; 70: 227-231

19) Castelli WP: The triglyceride issue: a view from Framingham. Am Heart J, 1986; 112: 432-437

20) Wilson PW, D’Agostino RB, Levy D, Belanger AM, Silbershatz H, Kannel WB: Prediction of coronary heart disease using risk factor categories. Circulation, 1998; 97: 1837-1847

21) Walsh JM, Grady D: Treatment of hyperlipidemia in women. JAMA, 1995; 274: 1152-1158

22) Yang $Z$, Kozai $T$, van der Loo $B$, Viswambharan $H$, Lachat M, Turina MI, Malinski T, Luscher TF: HMGCoA reductase inhibition improves endothelial cell function and inhibits smooth muscle cell proliferation in human saphenous veins. J Am Coll Cardiol, 2000; 36: 1691-1697

23) Rezaie-Majd A, Prager GW, Bucek RA, Schernthaner GH, Maca T, Kress HG, Valent P, Binder BR, Minar E, Baghestanian M: Simvastatin reduces the expression of adhesion molecules in circulating monocytes from hypercholesterolemic patients. Arterioscler Thromb Vasc Biol, 2003; 23: 397-403

24) Rezaie-Majd A, Maca T, Bucek RA, Valent P, Muller MR, Husslein P, Kashanipour A, Minar E, Baghestanian M: Simvastatin reduces expression of cytokines interleukin-6, interleukin-8, and monocyte chemoattractant protein-1 in circulating monocytes from hypercholesterolemic patients. Arterioscler Thromb Vasc Biol, 2002; 22: 11941199

25) Colhoun HM, Betteridge DJ, Durrington PN, Hitman GA, Neil HA, Livingstone SJ, Thomason MJ, Mackness MI, Charlton-Menys V, Fuller JH; CARDS investigators: Primary prevention of cardiovascular disease with atorvastatin in type 2 diabetes in the Collaborative Atorvastatin Diabetes Study (CARDS): multicentre randomised placebo-controlled trial. Lancet, 2004; 364: 685-696

26) Sever PS, Dahlof B, Poulter NR, Wedel H, Beevers G, Caulfield M, Collins R, Kjeldsen SE, Kristinsson A, McInnes GT, Mehlsen J, Nieminen M, O'Brien E, Ostergren J; ASCOT investigators: Prevention of coronary and stroke events with atorvastatin in hypertensive patients who have average or lower-than-average cholesterol concentrations, in the Anglo-Scandinavian Cardiac Outcomes Trial--Lipid Lowering Arm (ASCOT-LLA): a multicentre randomised controlled trial. Lancet, 2003; 361: 1149-1158

27) Nissen SE, Tuzcu EM, Schoenhagen P, Brown BG, Ganz P, Vogel RA, Crowe T, Howard G, Cooper CJ, Brodie B, Grines CL, DeMaria AN; REVERSAL Investigators: 
Effect of intensive compared with moderate lipid-lowering therapy on progression of coronary atherosclerosis: a randomized controlled trial. JAMA, 2004; 291: 10711080

28) Nissen SE, Tuzcu EM, Libby P, Thompson PD, Ghali M, Garza D, Berman L, Shi H, Buebendorf E, Topol EJ; CAMELOT Investigators: Effect of antihypertensive agents on cardiovascular events in patients with coronary disease and normal blood pressure: the CAMELOT study: a randomized controlled trial. JAMA, 2004; 292: 22172225

29) Nissen SE, Tuzcu EM, Brewer HB, Sipahi I, Nicholls SJ, Ganz P, Schoenhagen P, Waters DD, Pepine CJ, Crowe TD, Davidson MH, Deanfield JE, Wisniewski LM, Hanyok JJ, Kassalow LM; ACAT Intravascular Atherosclerosis Treatment Evaluation (ACTIVATE) Investigators: Effect of ACAT inhibition on the progression of coronary atherosclerosis. N Engl J Med, 2006; 354: 1253-1263

30) Nissen SE, Nicholls SJ, Sipahi I, Libby P, Raichlen JS, Ballantyne CM, Davignon J, Erbel R, Fruchart JC, Tardif JC, Schoenhagen P, Crowe T, Cain V, Wolski K, Goormastic M, Tuzcu EM; ASTEROID Investigators: Effect of very high-intensity statin therapy on regression of coronary atherosclerosis: the ASTEROID trial. JAMA, 2006; 295: 1556-1565

31) Ropers D, Rixe J, Anders K, Kuttner A, Baum U, Bautz W, Daniel WG, Achenbach S: Usefulness of multidetector row computed tomography with $64-\times 0.6-\mathrm{mm}$ collimation and 330-ms rotation for the noninvasive detection of significant coronary artery stenoses. Am J Cardiol, 2006; 97: 343-348 